\title{
Merkel cell carcinoma with an unusual immunohistochemical profile
}

\author{
L. Pilloni, ${ }^{1}$ C. Manieli, ${ }^{1}$ G. Senes, ${ }^{1}$ D. Ribuffo, ${ }^{2}$ G. Faa ${ }^{1}$ \\ ${ }^{1}$ Department of Cytomorphology, Division of Pathology; ${ }^{2}$ Department of Surgery, Section of Plastic \\ Surgery, University of Cagliari, Cagliari, Italy
}

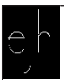

(C)2009 European Journal of Histochemistry

The clinical and morphological picture of Merkel cell carcinoma (MCC) may be rather challenging; therefore, the immunohistochemical profile plays a relevant role in confirming the microscopic diagnosis. A panel of antibodies including cytokeratins 20, 7 and epithelial membrane antigen, and neuronspecific enolase is used in confirming the morphological diagnosis of MCC. The majority of MCCs express CK20 and are CK7-negative. Herein, we present a case of primary cutaneous neuroendocrine carcinoma with an atypical immunohistochemical pattern. A 83-years old woman presented with a painless plaque, red to violaceous in colour, located in the leg. The skin tumor was excided, formalin-fixed and paraffinembedded. Tissue sections were immunostained with a panel of antibodies routinely utilized in complex primary skin tumors for evidencing epithelial and neuroendocrine differentiation of tumor cells. The neuroendocrine differentiation of tumor cells was evidenced by their immunoreactivity for synaptophysin, chromograninA and neuron-specific enolase. Tumor cells also showed diffuse cytoplasmic staining for CK7. No immunoreactivity was detected for CK20 and thyroid transcription factor-1. Our data, together with previous rare reports of CK20-/CK7+ MCCs, lay stress on the importance of routinely utilizing a panel of antibodies in the differential diagnosis of complex primary carcinomas of the skin and may have important implications in expanding the differential diagnosis of skin tumors. In particular, caution should be taken in excluding the diagnosis of MCC only on the basis of the absence of reactivity of tumor cells for CK20, favouring the wrong diagnosis of less aggressive skin tumors.

Key words: Merkel cell carcinoma, immunohistochemical profile, CK20 negative, CK7 positive.

Correspondence: Luca Pilloni,

Department of Cytomorphology, Division of Pathology, University of Cagliari, Italy

Tel.: 070.6092424.

Fax: 070.6092370.

E-mail: lucpilloni@tiscali.it

\section{Paper accepted on August 8, 2009}

European Journal of Histochemistry

2009; vol. 53 issue 4 (October-December): 275-278
$\mathrm{M}$ erkel cell carcinoma ( $\mathrm{MCC}$ ), also known as trabecular carcinoma or primary cutaneous neuroendocrine carcinoma, is a rare and very aggressive skin cancer. MCC is thought to be derived from pressure-sensing Merkel cells (Goessling et al., 2002; Schwartz et al., 2005); it is most commonly found in head and neck and in the upper extremities of individuals over 65. The clinical presentation of MCC is nonspecific, presenting as a painless, rapidly growing (Silva et al., 1984), red to violaceous plaque or nodule, usually less than $2 \mathrm{~cm}$ in diameter. MCC often recurs locally and has a propensity for both local and distant metastases via hematogenous and lymphatic routes. Locoregional recurrence rates range from 20\% to $80 \%$ (Tai et al., 2000; Goessling el al., 2002); metastasis occurs approximately in $50 \%$ of cases6, the skin being the main site of metastatic spread $(28 \%)$, followed by lymph nodes (27\%), liver (14\%) and lung (10\%) (Voog et al., 1999). The diagnosis of MCC is based upon the clinical presentation and on the histological picture, confirmed by immunohistochemical data. Microscopically, MCC appears as a blue cell tumor with small, round, monomorphic cells, with scant cytoplasm and a "salt and pepper" chromatin pattern. The cells may be arranged in a variety of patterns including solid, diffuse or trabecular structures. Defined by both neuroendocrine and epithelial differentiation, MCC displays immunoreactivity for epithelial membrane antigen (EMA) (Sibley et al., 1985), neurofilaments (Fantini et al., 1995), neuron-pecific enolase (NSE) (Gould et al., 1985), synaptophysin (Ortonne et al., 1988), chromogranin, neural cell adhesion molecule (NCAM/CD56) and cytokeratin (CK) 20 (Moll et al., 1995). Immunohistochemistry is essential in the diagnosis of MCC and in differentiating it from other tumors including: 
small cell carcinoma of the lung (SCCL), lymphoma, Ewing's sarcoma and salivary gland small cell carcinoma. Most MCCs stain positively for CK20 and are not reactive for CK7 (Jensen et al., 2000). At the best of our knowledge, just seven cases of CK20-negative and CK7 positive MCCs have been reported (Kenneth et al., 2007). Here we report a case of this rare variant of primary neuroendocrine $\mathrm{CK} 2 \mathrm{O}^{-} / \mathrm{CK} 7^{+}$carcinoma.

A 83-years old woman was admitted to our hospital (San Giovanni di Dio, Cagliari) for a painless, red to violaceous plaque, located in the leg. There was no previous history of irradiation. A wide excision of the lesion, including grossly free margins, was performed.

The lesion measured $5 \mathrm{~mm}$ in its greatest diameter and extended in depth up to $8 \mathrm{~mm}$. Microscopically, the tumor was superficially locat- ed but not connected to the epidermis. It showed a trabecular dermal population of epithelioid cells with enlarged nuclei characterized by a "salt and pepper" chromatin pattern (Figure $1 \mathrm{a}$ ), and a brisk mitotic rate, in the absence of necrosis. Neuroendocrine differentiation was evidenced by immunoreactivity of tumor cells for synaptophysin, chromograninA and NSE (Figure Ib). In addition, cancer cells showed diffuse cytoplasmic staining for CK7 (Figure 1c). CK20 (Figure 1d) and TTF-1 staining were negative. Clinical work up for metastatic disease including CT scan of the thorax was negative. No evidence of metastatic disease was present at a 6 months follow up.

Primary cutaneous neuroendocrine carcinoma was initially described as a distinct entity by Toker in 1982 (Toker, 1982). Thirty seven years later, the origin and histogenesis of MCC remains contro-
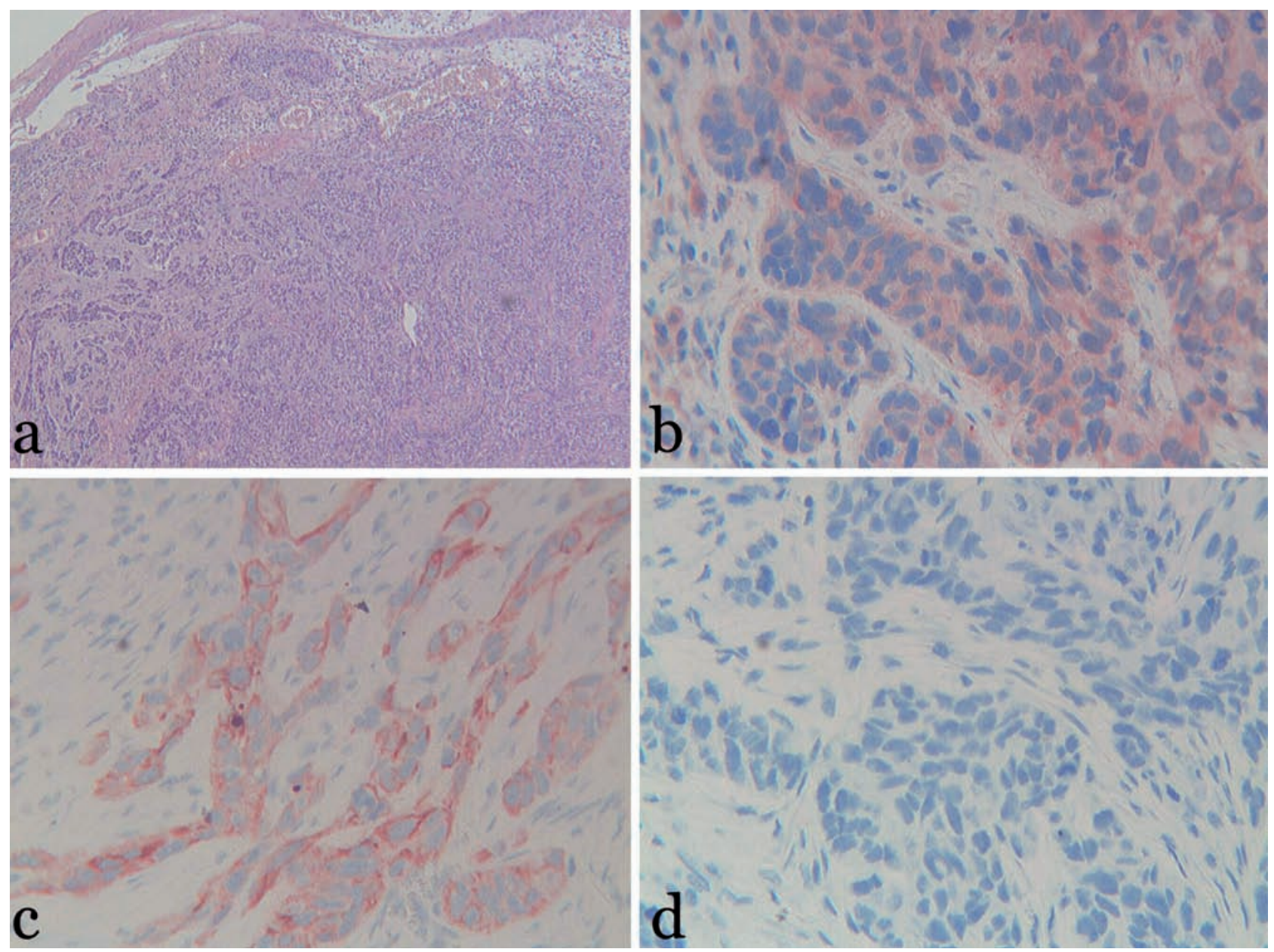

Figure 1. Merkel cell carcinoma: (a) MCC showing nests of deeply basophilic proliferating cells within the papillary and reticular dermis. (hematoxylin and eosin; 4x, original magnification); (b) a ribbon-like (trabecular) growth pattern cells positive for NSE (25x, original magnification); (c) cells diffusely positive for Ck7 (25x, original magnification); (d) absent immunoreactivity for Ck 20 (25x, original magnification). 
versial. Suggested origins of MCC include sweat gland epithelium, Merkel cell and pluripotent cells in the epidermis and/or dermis (Brwon et al., 2000). The description of granules in MCC has been described as indistinguishable from those seen in cells of neural crest derivation, suggesting the origin of MCC from Merkel cells (Silva et al., 1984). Merkel cells are known to be CK20-positive; only in a subset of MCC CK7 immunoreactivity has also been described (Yao et al., 2002). The diagnosis of MCC can be both clinically and histologically challenging. The clinical presentation is rather non-specific and lesions initially interpreted as basal cell carcinoma or squamous cell carcinoma (SCC) can be later diagnosed as MCC, based upon the immunohistochemical findings. Immunohistochemistry focused upon both the epithelial and neuroendocrine differentiation of $\mathrm{MCC}$, has now become essential in confirming the diagnosis of this tumor. CK20 positivity and CK7 negativity is considered the typical immunohistochemical profile useful in confirming the diagnosis of MCC. CK20 is an intermediate filament protein whose expression is primarily restricted to gastric and intestinal epithelium (Botta et al., 2001), urothelium, taste buds of the tongue and Merkel cells (Moll and Franke, 1985; Moll et al., 1995). CK20 staining in MCC is described as having a characteristic perinuclear punctuate staining pattern. Cutaneous SCC, basal cell carcinoma and melanoma have been shown to be negative for CK20 (Moll and Franke, 1985). Bobos et al. reported that CK20 was expressed in $87 \%$ of MCCs (339/391), while in SCCL CK20 immunoreactivity was showed only in 14 of 302 cases (4.6\%) (Bobos et al., 2006).

Our case showed a peculiar immunohistochemical profile: synaptophysin, chromogranin, NSE positivity, CK20 negativity and immunoreactivity for CK7. CK7, a member of the basic type II CKs, is mainly found in glandular epithelia and in transitional epithelia (Kenneth et al., 2007). CK7 has been reported to be expessed in association with CK20 in 23-31\% of MCCs (Bobos et al., 2006). In a review of the literature, there are documented cases of $\mathrm{CK} 20+/ \mathrm{CK} 7+, \mathrm{CK} 20+/ \mathrm{CK} 7-\mathrm{CK} 20-$ /CK7- MCCs (Jensen et al., 2000). Only seven cases, at the best of our knowledge, with the CK20-/CK7+ profile have been described (Kenneth et al., 2007). The significance of the immunophenotype CK20-/CK7+ in a primary neu- roendocrine carcinoma is yet to be determined. Merkel cells are known to be $\mathrm{CK} 2 \mathrm{O}^{+}$and in a review of the literature $\mathrm{CK} 7$ immunoreactivity has also been described in a subset of Merkel cells (Yao et al., 2002).

The absence of reactivity for $\mathrm{CK} 20$ and the aberrant expression of $\mathrm{CK} 7$, absent in normal Merkel cells, could identify a subset of MCCs originating from dedifferentiated Merkel cells. According to Kenneth et al. (2007), the findings of positive CK7 staining in MCC carcinoma may further define/expand the immunohistochemical profile of this neoplasm while supporting a possible derivation from Merkel cells. Finally, from a practical point of view, our case underlines that caution should be taken in excluding the diagnosis of MCC only on the basis of the absence of immunoreactivity for CK20, favoring the wrong diagnosis of less aggressive skin tumors.

\section{References}

Bobos M, Hytiroglou P, Kostopoulos I, Karkavelas G, Papadimitriou CS. Immunohistochemical distinction between Merkel cell carcinoma and small cell carcinoma of the lung. Am J Dermatopathol 2006;28: 99-104.

Botta MC, Ambu R, Liguori C, Van Eyken P, Pisanu A, Cabras A, et al. CK20 expression in the gastrointestinal tract of the embryo and fetus. Pathologica 2001;93:640-4.

Brwon HA, Sawyer DM, Woo T. Intraepidermal Merkel cell carcinoma with no dermal involvement. Am J Dermatopathol 2000;22: 65-9.

Fantini $F$, Johansson 0 . Neurochemical markers in human cutaneous Merkel cells. An immunohistochemical investigation. Exp Dermatol 1995; 4:365-71.

Goessling W, McKee PH, Mayer RJ. Merkel cell carcinoma. J Clin Oncol 2002;20:588-98.

Gould VE, Moll R, Moll I, Lee I, Franke WW. Biology of disease. Neuroendocrine (Merkel) cells of the skin: hyperplasias, dysplasias, and neoplasms. Lab Invest 1985;52:334-53.

Jensen K, Kholer S, Rouse RV. Cytokeratin staining in Merkel cell carcinoma: an immunohistochemical study of Cytokeratins 5/6, 7, 17 and 20. Appl Immunohistochem Mol Morphol 2000;8:310-5.

Calder KB, Coplowitz S, Schlauder S, Morgan MB. A case series and immunophenotypic analysis of $\mathrm{CK} 20-/ \mathrm{CK} 7+$ primary neuroendocrine carcinoma of the skin. J Cutan Pathol 2007;34:918-23-

Moll I, Kuhn C, Moll R. Cytokeratin 20 is a general marker of cutaneous Merkel cells while certain neuronal proteins are absent. J Invest Dermatol 1995;104:910-5.

Moll R, Franke WW. Cytoskeletal differences between human neuroendocrine tumors: a cytoskeletal protein of molecular weight 46,000 distinguishes cutaneous from pulmonary neuroendocrine neoplasms. Differentiation 1985;30:165-75.

Ortonne JP, Petchot-Bacque JP, Verrando P, Pisani A, Pautrat G, Bernerd F. Normal Merkel cells express a synaptophysin-like immunoreactivity. Dermatologica 1988;177:1-10.

Sibley RK, Dahl D. Primary neuroendocrine (Merkel cell?) carcinoma of the skin. II. An immunocytochemical study of 21 cases. Am J Surg Pathol 1985;9:109-16.

Schwartz RA, Lambert WC. The Merkel cell carcinoma: a 50-year retrospect. J Surg Oncol 2005;89:5.

Sidhu GS, Feiner H, Flotte TJ, Mullins JD, Schaefler K, Schultenover 
SJ. Merkel cell neoplasms. Am J Dermatopathol 1980;2:101-9.

Silva EG, Mackay B, Goepfert H, Burgess MA, Fields RS. Endocrine carcinoma of the skin (Merkel cell carcinoma). Pathol Annu 1984;19:1-30.

Tai PT, Yu E, Winquist E, Hammond A, Stitt L, Tonita J, et al. Chemotherapy in neuroendocrine/Merkel cell carcinoma of the skin: case series and review of 204 cases. J Clin Oncol 2000;18:2493-9.

Toker C. Trabecular carcinoma of the skin. Am J Dermatopathol
1982;4:497-500.

Voog E, Biron P, Martin JP, Blay JY. Chemotherapy for patients with locally advanced or metastatic Merkel cell carcinoma. Cancer 1999;85:2589-95.

Yao DX, Hoda SA, Chiu A, Ying L, Rosen PP. Intraepidermal cytokeratin 7 immunoreactive cells in the non-neoplastic nipple may represent interepithelial extension of lactiferous duct cells. Histopathology 2002;40:230-6. 